\title{
Amyloid Precursor Protein Mediates Neuronal Protection from Rotenone Toxicity
}

\author{
Kathryn Cimdins ${ }^{1,2} \cdot$ Hayley S. Waugh ${ }^{1,2} \cdot$ Vicki Chrysostomou ${ }^{1,2} \cdot$ M. Isabel G. Lopez Sanchez ${ }^{1,2}$. \\ Vanessa A. Johannsen ${ }^{3}$. Mark J. Cook ${ }^{4,5}$. Jonathan G. Crowston ${ }^{1,2}$. Andrew F. Hill ${ }^{6}$. James A. Duce ${ }^{7,8}$. \\ Ashley I. Bush ${ }^{8} \cdot$ Ian A. Trounce ${ }^{1,2,4}$
}

Received: 23 September 2018 / Accepted: 17 December 2018 / Published online: 5 January 2019

(C) The Author(s) 2019

\begin{abstract}
Mitochondrial complex I dysfunction is the most common respiratory chain defect in human disorders and a hotspot for neurodegenerative diseases. Amyloid precursor protein (APP) and its non-amyloidogenic processing products, in particular soluble APP $\alpha(\operatorname{sAPP} \alpha)$, have been shown to provide neuroprotection in models of neuronal injury; however, APP-mediated protection from acute mitochondrial injury has not been previously reported. Here, we use the plant-derived pesticide rotenone, a potent complex I-specific mitochondrial inhibitor, to discover neuroprotective effects of APP and sAPP $\alpha$ in vitro, in neuronal cell lines over-expressing APP, and in vivo, in a retinal neuronal rotenone toxicity mouse model. Our results show that APP overexpression is protective against rotenone toxicity in neurons via SAPP $\alpha$ through an autocrine/paracrine mechanism that involves the Pi3K/Akt pro-survival pathway. $\mathrm{APP}^{-/-}$mice exhibit greater susceptibility to retinal rotenone toxicity, while intravitreal delivery of $\operatorname{sAPP} \alpha$ reduces inner retinal neuronal death in wild-type mice following rotenone challenge. We also show a significant decrease in human retinal expression of APP with age. These findings provide insights into the therapeutic potential of non-amyloidogenic processing of APP in complex I-related neurodegeneration.
\end{abstract}

Keywords Mitochondria $\cdot$ Amyloid precursor protein $\cdot$ Neuroprotection $\cdot$ Rotenone $\cdot$ Complex I $\cdot$ Retina

\section{Introduction}

Mitochondrial complex I (NADH/ubiquinone oxidoreductase) is the main entry point of electrons into the respiratory chain from carbohydrate metabolism, via the oxidation of NADH. Complex I is the largest of the five oxidative

Electronic supplementary material The online version of this article (https://doi.org/10.1007/s12035-018-1460-7) contains supplementary material, which is available to authorized users.

Ian A. Trounce

i.trounce@unimelb.edu.au

1 Centre for Eye Research Australia, Royal Victorian Eye and Ear Hospital, Melbourne, Victoria, Australia

2 Ophthalmology, Department of Surgery, The University of Melbourne, 75 Commercial Road, Melbourne, Victoria 3004, Australia

3 Department of Oncology, University of Oxford, Oxford, UK

4 Department of Medicine, St. Vincent's Hospital, The University of Melbourne, 75 Commercial Road, Melbourne, Victoria 3004, Australia phosphorylation (OXPHOS) enzymes, comprising 45 protein subunits including 7 encoded in the mitochondrial DNA [1, 2]. Within mitochondrial disorders, complex I defects account for a disproportionate majority of disease, which range in clinical severity from Leber hereditary optic neuropathy with specific retinal ganglion cell loss, to severe multisystem

Centre for Clinical Neuroscience and Neurological Research, St. Vincent's Hospital, Melbourne, Victoria, Australia

6 Department of Biochemistry and Genetics, La Trobe Institute for Molecular Science, La Trobe University, Melbourne, Victoria, Australia

The ALBORADA Drug Discovery Institute, Cambridge Biomedical Campus, University of Cambridge, Cambridge, UK

8 The Florey Institute of Neuroscience and Mental Health, The University of Melbourne, Melbourne, Victoria, Australia 
progressive and lethal encephalopathies [2-4]. Partial systemic complex I defects have been demonstrated in Parkinson's disease [5], glaucoma [6, 7], and in Leber hereditary optic neuropathy [8]. The plant-derived pesticide rotenone is a potent complex I-specific inhibitor that is widely used to model Parkinson's disease and optic neuropathies both in vitro and in vivo [9-11].

The primary clinical presentations in Parkinson's disease are motor symptoms such as bradykinesia and resting tremor, but the disease also routinely involves non-motor symptoms such as visual and olfactory deficits. Recent work has evidenced retinal thickness as an accessible biomarker given that thinning of the retinal layer is an early event in Parkinson's disease [12] and continued thinning corresponds both with the progression of disease symptoms [13] and nigral dopaminergic loss [14]. It is generally accepted that the causal origin of Parkinson's disease is unknown in most cases. A series of molecular mechanisms, including mitochondrial dysfunction, oxidative stress, excitotoxic damage, and loss of protective proteins, are hypothesized as early, contributing, interacting, and/or causal events [15].

The amyloid precursor protein (APP) is the parent protein of a complex family of derivative peptides that exert various neuroprotective activities [16, 17]. APP is predominantly processed from its membrane-bound holoform via two pathways. The favored non-amyloidogenic pathway produces a large N-terminal ectodomain, soluble APP $\alpha(\operatorname{sAPP} \alpha)$, which is secreted into the extracellular medium [18], and a Cterminal fragment, which undergoes further processing to generate a peptide called p3 [19]. Alternatively, amyloidogenic APP processing results in the release of a shorter ectodomain called soluble APP $\beta$ into the extracellular medium, and a 99amino acid C-terminal fragment in the membrane [20]. Further cleavage of this $\mathrm{C}$-terminal fragment generates the amyloid $\beta$ (A $\beta$ ) peptide found in cerebral plaques of neuropathological diseases such as Alzheimer's disease [21, 22].

Non-amyloidogenic APP processing has been shown to provide neuroprotection in models of neuronal injury, including traumatic brain injury and ischemia-reperfusion injury [23-25]. APP-mediated protection from acute mitochondrial injury has not been previously described. Here, we use the plant-derived pesticide rotenone, a potent complex I-specific inhibitor, and Parkinson's disease mimetic, to discover neuroprotective effects of APP and SAPP $\alpha$ in vitro and in vivo and provide mechanistic insights into the role of APP in counteracting mitochondrial neurotoxic stress.

\section{Materials and Methods}

\section{Cell Culture and Plasmid Transfection}

Human neuroblastoma SH-SY5Y, mouse neuroblast neuro2-a (N2a), or Chinese hamster ovary $(\mathrm{CHO})$ cells were grown in
RPMI 1640 medium (Cat. \#11875, Thermo Fisher Scientific) and supplemented with $10 \%$ fetal bovine serum (FBS) in a humidified incubator at $37{ }^{\circ} \mathrm{C}$ and $5 \% \mathrm{CO}_{2}$. Cells were transfected with a pIRESpuro2 empty vector control (Clontech Laboratories Inc., Takara-Bio Inc., Japan) or a vector containing human wild-type full-length $\mathrm{APP}_{695}$ isoform (hereafter referred to as "control" or "APP" respectively) as described previously [26]. Cells were transferred to glucosefree RPMI 1640 medium (Thermo Fisher Scientific, Cat. \#11879) supplemented with 7.5\% FBS and 5.6 mM glucose (euglycemic medium) $24 \mathrm{~h}$ prior to rotenone treatment, because hyperglycemia can selectively reduce physiological $\alpha$ secretase cleavage of APP [27].

\section{Ethics}

All procedures conformed to the requirements of the Royal Victorian Eye \& Ear Hospital Animal Research and Ethics Committee. Wild-type and $\mathrm{APP}^{-/-}$mice on a SV129 background [28] originated from a breeding colony at the Melbourne Brain Centre, Melbourne VIC, Australia. Mice were housed in a temperature $\left(22 \pm 1^{\circ} \mathrm{C}\right)$ and light $(12 \mathrm{~h}$ light, $12 \mathrm{~h}$ dark) controlled environment where food and water were available ad libitum. Male and female mice were used equally.

\section{Human Eye Collection and Processing}

Work involving human eyes was carried out in accordance of the Declaration of Helsinki. All experimental procedures were approved by the Royal Victorian Eye and Ear Hospital Human Research Ethics Committee (Project 08/859H) and written informed consent was obtained from all next of kin or participants. Human eyes were donated for research purposes through the Lions Eye Donation Service (Melbourne, Australia). Information was received in relation to the donor's medical history including cause of death, time of death, past illnesses and any relevant eye history if known.

\section{Experimental Treatments and Co-culture}

Rotenone (Sigma-Aldrich) was dissolved in ethanol and potassium cyanide (KCN; Sigma-Aldrich) was dissolved in ultrapure MilliQ water. Wortmannin (Sigma-Aldrich; $20 \mathrm{nM}$; wmn) was added to cells $1 \mathrm{~h}$ before rotenone treatment. Coculture of SH-SY5Y control and APP cells was achieved using a ThinCert apparatus (Greiner Bio-One, USA, $1 \mu \mathrm{m}$ membrane).

Briefly, control SH-SY5Y cells were seeded in 24-well culture plates (main well) and control or APP-overexpressing SH-SY5Y cells were plated into Thincert inserts (insert; Greiner Bio-One, USA) for $40 \mathrm{~h}$ prior to rotenone exposure. Co-culturing occurred for $16-8 \mathrm{~h}$ prior to rotenone treatment to allow secreted APP fragments to move freely 
between culture populations by diffusion while preventing direct interaction of both cell types.

\section{In Vivo Rotenone Toxicity Model}

Mice were anesthetized by intraperitoneal injection of ketamine $(60 \mathrm{mg} / \mathrm{kg})$ and xylazine $(10 \mathrm{mg} / \mathrm{kg})$. After making a guide track through the conjunctiva and sclera at the superior temporal hemisphere using a 30-gauge needle, a hand-pulled glass micropipette was inserted into the mid-vitreal cavity. Rotenone (1 $\mu \mathrm{l} ; 10 \mathrm{mM}$; Sigma-Aldrich) or vehicle (DMSO) was injected into the vitreal chamber at a rate of $100 \mathrm{nl} / \mathrm{s}$ using an Ultra Micro Pump (World Precision Instruments, Inc. Sarasota, USA). Patency was confirmed following needle removal. For sAPP $\alpha$ co-treatment experiments, a second intravitreal injection of recombinant human $\operatorname{sAPP} \alpha(6 \mathrm{ng} / \mu \mathrm{l}$, Sigma-Aldrich) or vehicle (phosphate-buffered saline; PBS) was performed $30 \mathrm{~min}$ after injection of rotenone.

\section{Cell Viability and Caspase 3 Assay}

Cell viability and proliferation were measured by the trypan blue exclusion assay. Cells seeded at equal densities were scraped and collected by centrifugation $(1000 \mathrm{~g}, 5 \mathrm{~min})$, suspended in PBS, and a 10- $\mu$ l aliquot mixed with an equal volume of $0.4 \%$ trypan blue solution (Cat \# 1525006, Thermo Fisher Scientific) and counted using a hemocytometer. For caspase 3 activity analysis, cells were collected following rotenone treatment and lysed in lysis buffer (50 mM HEPES, pH 7.4, $150 \mathrm{mM} \mathrm{NaCl}, 1 \mathrm{mM}$ EDTA, 0.2 mM EGTA, $1 \%$ Triton X-100, $1 \mathrm{mM}$ phenylmethylsulfonyl fluoride, $10 \mu \mathrm{g} / \mathrm{ml}$ aprotinin, $5 \mu \mathrm{M} \mathrm{Na}_{3} \mathrm{VO}_{4}$ ), passed twice through a $21 \mathrm{G}$ needle, incubated on ice for $10 \mathrm{~min}$, and the supernatant collected by centrifugation $(10,000 \mathrm{~g}, 10 \mathrm{~min})$. A $50-\mu \mathrm{l}$ aliquot of this lysate was used to measure caspase-3 activity using the EnzChek Caspase-3 Assay kit (Molecular Probes, USA) according to manufacturer's instructions.

\section{Reactive Oxygen Species Generation}

ROS were measured using 2,7-dichlorodihydrofluorescein (DCFH) - to detect hydrogen peroxide — and dihydroethidine (DHE) - to detect superoxide, with a Polarstar fluorescence microplate reader (POLARstar OPTIMA, BMG laboratories, Australia) by measuring fluorescence with excitation and emission wavelengths of $480 \pm 10$ and $570 \pm 10 \mathrm{~nm}$, respectively. Briefly, cells were plated at $5 \times 10^{4}$ in 96 -well plates in euglycemic medium for $24 \mathrm{~h}$ prior to treatment for up to $24 \mathrm{~h}$, media was removed, and cells incubated in the dark with DCFH or DHE for $30 \mathrm{~min}$ at $37^{\circ} \mathrm{C}$. Cells were then washed twice with PBS and suspended in PBS for fluorescence analysis. A total of $100 \mathrm{nM}$ phorbol 12-myristate 12-acetate dissolved in DMSO was used as a positive control for superoxide detection, while $1 \mathrm{mM} \mathrm{H}_{2} \mathrm{O}_{2}$ was used as a positive control for hydrogen peroxide detection.

\section{ATP Synthesis}

ATP quantification was carried out using the ATP Determination Kit Assay (Cat. \# A22066, Thermo Fisher Scientific) according to manufacturer's instructions, with a Polarstar fluorescence microplate reader (POLARstar OPTIMA, BMG laboratories, Australia).

\section{Protein Extraction to Determine Phosphorylation State}

Harvested cells were collected by centrifugation $(1000 g$, $3 \mathrm{~min}, 4^{\circ} \mathrm{C}$ ) and suspended in lysis buffer containing $50 \mathrm{mM}$ Tris- $\mathrm{HCl} \mathrm{pH}$ 7.4, $150 \mathrm{mM} \mathrm{NaCl}, 1 \mathrm{mM}$ EDTA, $1 \%$ Tergitol, $0.1 \%$ SDS in milliQ H2O, $2 \mathrm{mM}$ activated sodium orthovanadate $\left(\mathrm{Na}_{3} \mathrm{VO}_{4}\right), 1 \mathrm{mM}$ (PMSF), and aprotinin $10 \mu \mathrm{g} / \mathrm{ml}$. Samples were sonicated on ice (3 pulses at power setting 1.5, $0.04 \mathrm{~V}$, Milsonix homogenizer, Milsonix Inc., USA) and snap-frozen at $-80{ }^{\circ} \mathrm{C}$ for $2 \mathrm{~h}$. Lysed cells in the supernatant were collected by centrifugation $(1000 \mathrm{~g}, 30 \mathrm{~s}$, $\left.4{ }^{\circ} \mathrm{C}\right)$.

\section{Immunoblotting}

Harvested cells, retina, or vitreous were suspended in 70$100-\mu l$ lysis buffer, sonicated on ice (as described above), and incubated on ice for $30 \mathrm{~min}$, followed by centrifugation $\left(18,000 \mathrm{~g}, 20 \mathrm{~min}, 4^{\circ} \mathrm{C}\right)$ to collect the supernatant containing protein. Immunoblotting was performed as described before [29] and protein expression was detected using primary antibodies: anti-APP 22C11 (\# MAB348, Millipore, 1:5000), anti-sAPP $\alpha$ 2B3 (\#11088, IBL, 1:2000), anti-Akt (\#9272, Cell Signaling, 1:5000), antiphospho-Akt Ser473 (\#9271, Cell Signaling, 1:2000), anti-phospho-Akt Thr308 (\#9275, Cell Signaling, 1:2000), anti-phospho-ERK1/2 (Cell Signaling, 1:2000), anti-phospho-JNK (Cell Signaling, 1:1000), antiphospho-p38 (Cell Signaling, 1:1000), anti-actin antibody (Sigma-Aldrich, 1:5000). Primary antibodies were detected using sheep anti-mouse or anti-rabbit horseradish peroxidase-conjugated secondary antibody (Amersham GE Healthcare, Cat \# NA931V or \#NA934) and visualized by electrochemiluminescence detection reagent on film (Amersham GE Healthcare, Cat \# RPN2106). Protein band intensities were measured using ImageJ software (https:// imagej.nih.gov/ij/), and band intensity determined in the linear range was normalized to band intensity of actin. 


\section{Collection and Processing of Mouse Retinal Tissue}

Eyes were enucleated and immersion-fixed in $4 \%$ paraformaldehyde for $3 \mathrm{~h}$, followed by overnight cryoprotection in $15 \%$ sucrose. Eyes were embedded in optical cutting temperature medium and $12 \mu \mathrm{m}$ sections were cut through the papillaryoptic nerve axis.

\section{Mouse Retina Imaging and TUNEL Assay}

Cryosections were immunolabeled with an antibody that recognizes the N-terminal of APP (22C11, 1:100, Merck Millipore) according to published protocols [30]. All sections were nuclear-counterstained with Hoechst $(1: 10,000)$. The thicknesses of cellular and synaptic retinal layers were measured on digital images of Hoechst-stained cryosections as described [31]. To quantify retinal ganglion cells, sections cut through the optic nerve head and ora serrate were scanned from superior to inferior edge and the numbers of Hoechstlabeled nuclei in the ganglion cell layer were counted. Retinal cryosections were labeled using the TUNEL assay according to published protocols [32]. Labeled sections were scanned from superior to inferior edge in 1-mm increments and the number of TUNEL-positive nuclei were recorded. The frequency of TUNEL-positive profiles/mm of retina was averaged from at least two sections per animal.

\section{Statistical Analysis}

Results are presented as the mean $\pm \mathrm{SD}$ or $\pm \mathrm{SEM}$ (indicated in the legend). Statistical analysis was performed with Prism 5.01 software (GraphPad Software Inc.) using Student's $t$ test, one-way ANOVA with Bonferroni correction for multiple comparisons or linear regression. Normal distribution of experimental measurements was determined by the ShapiroWilk test. A $P$ value $<0.05$ was considered as significant.

\section{Results}

\section{APP Protects Against Rotenone Toxicity in Neuronal Cells}

We investigated the effect of APP over-expression in the loss of neurons upon exposure to the mitochondrial neurotoxin and Parkinson's disease mimetic rotenone [33, 34]. Human neuroblastoma SH-SY5Y, mouse neuroblastoma $\mathrm{N} 2 \mathrm{a}$, or non-neuronal $\mathrm{CHO}$ cells were transfected with an empty vector (control) or a vector containing full-length, wild-type $\mathrm{APP}_{695}$ (APP). APP protein levels were measured by immunoblotting in SHSY-5Y, N2a, and $\mathrm{CHO}$ cells to demonstrate higher APP expression relative to control cells (Supplementary Fig. 1A). Transfected cell lines were exposed to increasing concentrations of rotenone for $48 \mathrm{~h}$ and cell survival was determined by the trypan blue exclusion assay (Fig. 1a). APP over-expression correlated with reduced cell loss in both SH-SY5Y and N2a cells compared to control cells, while no changes in cell survival were detected in CHO cells over-expressing APP. This protective effect was confirmed in transfected SH-SY5Y cells exposed to $100 \mathrm{nM}$ rotenone up to $96 \mathrm{~h}$, showing sustained protection in neuronal cells expressing higher levels of APP (Fig. 1b). APP protein levels were consistently higher in SHSY5Y cells transfected with APP upon exposure to increasing concentrations of rotenone (Supplementary Fig. 1B). This was consistent with significantly higher activation of caspase 3 in control cells compared with APP overexpressing cells at 16 and $24 \mathrm{~h}$ following rotenone challenge (Fig. 1c).

It is well established that $\mathrm{sAPP} \alpha$, resulting from the non-amyloidogenic cleavage of APP and released into the extracellular medium, is neuroprotective and neurotrophic [16]. To determine the paracrine neuroprotective potential of APP against rotenone-induced cell loss, control SHSY5Y cells were co-cultured with control cells (control/ control) or with APP cells (control/APP) for $16 \mathrm{~h}$ prior to rotenone exposure, in a transwell culture system that allowed secreted APP fragments to move freely between culture populations but prevented direct interaction of the different cell types (Supplementary Fig. 1C). Control/ control or control/APP co-cultures were exposed to rotenone $(100 \mathrm{nM})$ for $48 \mathrm{~h}$ and cell survival was determined by the trypan blue exclusion assay (Fig. 1d). sAPP $\alpha$ levels were increased in conditioned media from control/APP cocultures as measured by immunoblotting (Supplementary Fig. 1D). Cells continually exposed to $\operatorname{sAPP} \alpha$-enriched media through co-culture were significantly protected against rotenone-induced cell loss compared to control/ control cells (Fig. 1d). This was further explored by measuring caspase 3 activity, which was significantly higher in control/control co-cultures compared with control/APP cocultures, indicating that an activation of apoptotic pathways in control/control cells is absent in control/APP cells (Fig. 1e).

Next, we investigated the specificity of APP-mediated protection from mitochondrial toxicity, particularly OXPHOS complex IV inhibition, which has also been associated with age-related neurodegeneration [35]. Transfected cells were exposed to increasing concentrations of the complex IV inhibitor potassium cyanide (KCN) for $48 \mathrm{~h}$ and cell survival was assessed by the trypan blue exclusion assay (Supplementary Fig. 2). Unlike the complex I inhibition experiments, APP over-expression did not protect neuronal or non-neuronal cells from complex IV inhibition-induced toxicity (Supplementary Fig. 2A) or caspase 3 activation (Supplementary Fig. 2B). Furthermore, cellular ATP levels 


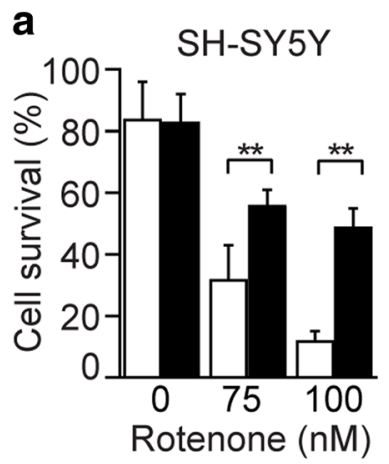

b

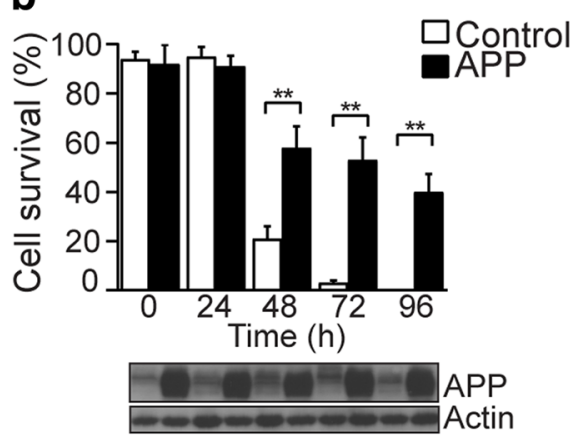

d

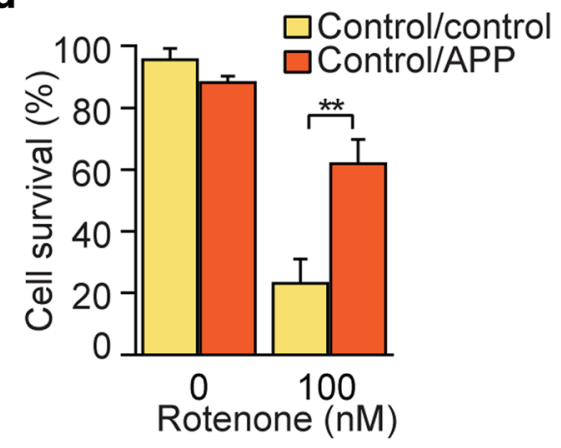

Fig. 1 APP protects against rotenone toxicity in neuronal cells. a Human neuroblastoma SH-SY5Y, mouse neuroblastoma N2a or non-neuronal CHO cells transfected with APP (APP) or empty vector control (control) were exposed to increasing concentrations of rotenone for $48 \mathrm{~h}$ and cell survival was determined by the trypan blue exclusion assay. SH-SY5Y and N2a cells transfected with APP had a significantly higher survival compared to control. b Cell survival in transfected SH-SY5Y cells exposed to $100 \mathrm{nM}$ rotenone was assessed up to $96 \mathrm{~h}$ to show sustained protection in SH-SY5Y cells expressing APP. Representative immunoblot showing increased APP levels in SH-SY5Y cells exposed to rotenone at each timepoint is included below the graph. Actin was used as
C

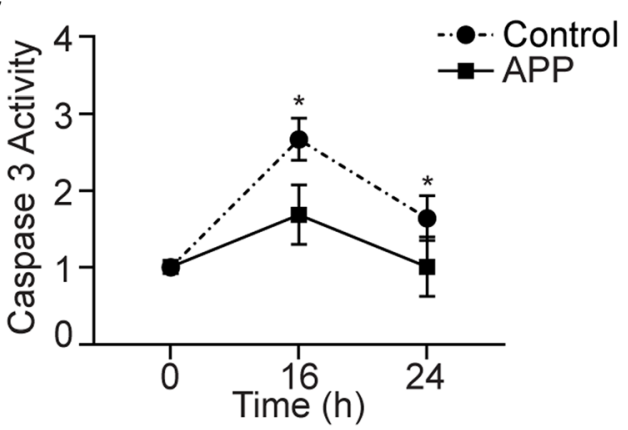

e

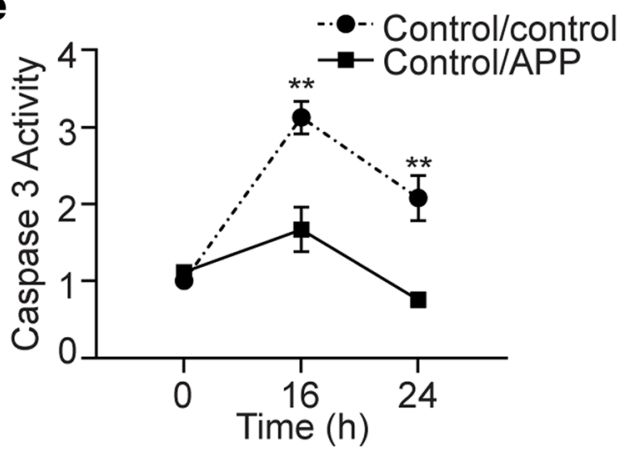

a loading control. c Caspase 3 activity is significantly higher in control SH-SY5Y cells 16 and $24 \mathrm{~h}$ post-exposure to $100 \mathrm{nM}$ rotenone compared to SH-SY5Y cells expressing APP. d Co-culture of control SH-SY5Y with SH-SY5Y cells expressing APP cells increases resistance to rotenone toxicity. Control SH-SY5Y cells were co-cultured with either SHSY5Y APP cells (control/APP) or control (control/control) for $16 \mathrm{~h}$ before incubation with vehicle or rotenone $(100 \mathrm{nM})$ for $48 \mathrm{~h}$ and cell survival was determined by the trypan blue exclusion assay. e Caspase 3 activity is significantly higher in control/control cells compared with control/APP cells 16 and $24 \mathrm{~h}$ post-exposure to $100 \mathrm{nM}$ rotenone. Data show mean \pm SD, $n \geq 4$, Student's $t$ test, $* P<0.05$, ** $P<0.01$. decreased at similar levels between control and APP transfected cells upon exposure to potassium cyanide (Supplementary Fig. 2C). Together, these results indicate that APP confers protection to neuronal cells from complex I toxicity induced by exposure to rotenone through an autocrine (i.e., intracellular APP over-expression) or paracrine (i.e., derived from secreted APP in co-culture) mechanism. This protection appears to be neuron-selective and specific to complex I.

\section{APP Prevents Rotenone-Induced Changes in Mitochondrial ROS and ATP Production}

Rotenone inhibits complex I of the mitochondrial electron transport chain and induces apoptosis via reduction of ATP synthesis and increased ROS production [36]. Therefore, to identify the mechanism of APP-mediated neuroprotection from rotenone toxicity in mitochondria, ATP and ROS levels were examined in control or APP SH-SY5Y cells incubated 
with $100 \mathrm{nM}$ rotenone for up to $24 \mathrm{~h}$ (Fig. 2). Over-expression of APP suppressed superoxide levels significantly between 1 and $16 \mathrm{~h}$ (Fig. 2a) and peroxide levels at 16 and $24 \mathrm{~h}$ following rotenone challenge (Fig. 2b). Basal ATP levels were unchanged by the over-expression of APP relative to control cells up to $16 \mathrm{~h}$; however, at $24 \mathrm{~h}$ post-rotenone exposure, ATP levels were preserved at significantly higher levels in cells over-expressing APP compared with control (Fig. 2c). These results reflect a delayed effect of APP on mitochondrial metabolism that coincide with caspase 3 activation and loss of plasma membrane integrity in control cells (Fig. 1).

\section{Pi3K/Akt Activation Is Crucial to APP-Mediated Neuronal Protection from Rotenone Toxicity}

Exposure of neuronal cultures to $\operatorname{sAPP} \alpha$ has been shown to activate the Pi3K/Akt pro-survival pathway and thereby prevent apoptosis following trophic factor deprivation [37, 38], A $\beta$ toxicity [39], or proteasome inhibition [40]. To further investigate the neuroprotective mechanism in our model of rotenone-induced mitochondrial toxicity, Akt phosphorylation response was measured by immunoblotting in control or APP SH-SY5Y cells (Fig. 3a), and in control/control or control/APP co-cultures (Fig. 3b) upon exposure to rotenone for up to $24 \mathrm{~h}$. APP over-expression alone or exposure to $\operatorname{sAPP} \alpha$-enriched media progressively induced significant and sustained Akt activation, reaching up to a 3-fold increase relative to controls by $24 \mathrm{~h}$ (Fig. 3a, b). Next, we assessed the functional relevance of Akt activation in the survival associated with APP overexpression or exposure to $\mathrm{APP} \alpha$-enriched media, by blocking Akt activation using the Pi3K inhibitor wortmannin (wmn; Fig. $3 \mathrm{c}, \mathrm{d}$ ). We observed a consistent and significant reversal in cell survival after 24-h exposure to rotenone in both APP overexpressing cells (Fig. 3c) and control/APP co-cultures upon treatment (Fig. 3d) in the presence of wortmannin, demonstrating that Akt activation is crucial for neuronal protection in our experimental setting.

Others have shown that rotenone-induced apoptosis requires activation of MAPK signaling pathways such as JNK and p38 [38, 41]. Therefore, we investigated whether protection from rotenone toxicity in cells over-expressing APP could also result from suppression of pro-apoptotic targets upstream of Akt. Over-expression of APP did not significantly alter the rotenone-induced acute activation of 338 (Supplementary Fig. 3A), JNK (Supplementary Fig. 3B), or c-Jun (Supplementary Fig. 3C). Furthermore, over-expression of APP did not alter rotenone-induced activation of the pro-survival ERK signaling pathway (Supplementary Fig. 3D). Together, these results suggest that the mechanism of APP-mediated neuroprotection against rotenone is through the $\mathrm{Pi} 3 \mathrm{~K} / \mathrm{Akt}$ pro-survival pathway and independent of MAPK or ERK pathways.

\section{APP Protects Against Rotenone-Toxicity in the Mouse Retina}

We next sought to determine if the neuroprotective effect of APP or $\operatorname{sAPP} \alpha$ in vitro extended to an in vivo setting. APP immunoreactivity in the $\mathrm{C} 57 \mathrm{BL} / 6 \mathrm{~J}$ mouse retina was most prominent in somas of the ganglion cell layer (GCL) on the inner retinal surface (Fig. 4a, in red), concurring with previous reports [42]. Intravitreal delivery of rotenone is an established model of retinal toxicity in the mouse eye that selectively kills inner retinal neurons [11]. Using this model, we assessed mouse retinas $24 \mathrm{~h}$ after rotenone injection by the TUNEL technique, which identifies DNA damage characteristic of apoptosis, to estimate cell death. We found a significant increase in the frequency of TUNEL-positive nuclei in the ganglion and inner nuclear layers of rotenone-treated eyes compared to those injected with vehicle (Fig. $4 \mathrm{~b}$, c), confirming the toxicity model and its specificity to the inner retina. To test if $\operatorname{sAPP} \alpha$ was able to rescue retinal neurons against rotenone toxicity, we injected exogenous $\operatorname{sAPP} \alpha$ into the mouse eye 30 min post-rotenone injury. Administration of sAPP $\alpha$ significantly reduced the number of TUNEL-positive profiles in the mid and inner layers of the retina (Fig. 4b, c). There was no detectable difference in the number of TUNEL-positive cells between $\operatorname{sAPP} \alpha$-treated retinas and uninjured (vehicleinjected) retinas.

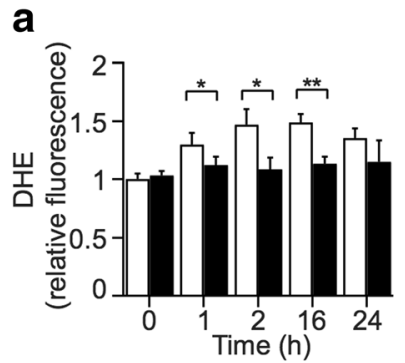

Fig. 2 APP alters rotenone-induced changes in mitochondrial ROS and ATP production. a, b Levels of cellular superoxide (a; DHE fluorescence) and hydrogen peroxide (b; DCFH fluorescence) were assessed in SHSY5Y control and APP cells treated with $100 \mathrm{nM}$ rotenone for up to
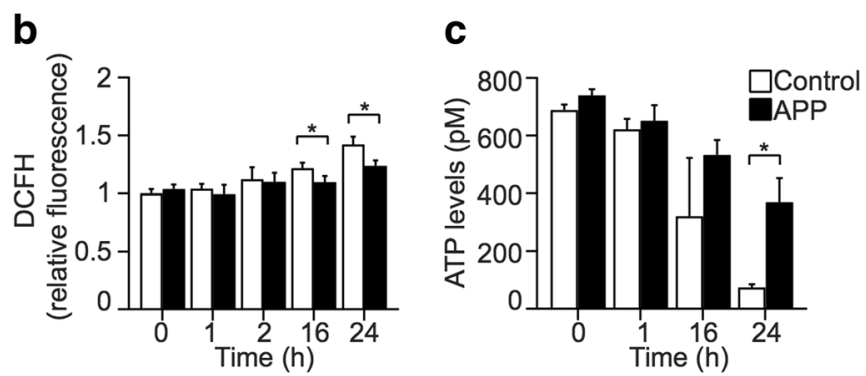

$24 \mathrm{~h}$. c Over-expression of APP in suppression of rotenone-induced levels of superoxide and hydrogen peroxide in APP over-expressing SH-SY5Y cells has delayed effects on ATP cellular levels. Data show mean \pm SD, $n \geq 3$, Student's $t$ test, $* P<0.05, * * P<0.01$ 
Fig. 3 Akt activation is crucial to APP-mediated neuronal protection from rotenone toxicity. $\mathbf{a}, \mathbf{b}$ In response to rotenone $(100 \mathrm{nM})$ exposure, Akt was activated in SH-SY5Y cells over-expressing APP (a) and in SH-SY5Y control/ APP co-cultures (b). c Cell survival was assessed in SH-SY5Y control or APP cells treated with rotenone $(75 \mathrm{nM} ; 48 \mathrm{~h})$ in the absence or presence of the Akt inhibitor wortmannin (w, wmn, $20 \mathrm{nM}$ ). d Cell survival was determined in SH-SY5Y control/ control or control/APP cocultures exposed to rotenone ( $75 \mathrm{nM} ; 48 \mathrm{~h}$ ) in the absence or presence of wortmannin (w, wmn, $20 \mathrm{nM}$ ). Representative blots and densitometric analyses show the ratio of activated

(phosphorylated, p-AKT) protein levels relative to unphosphorylated protein levels. Data show mean \pm SEM, $n \geq 3$, Student's $t$ test $(\mathbf{a}, \mathbf{b})$ or one-way ANOVA $(\mathbf{c}, \mathbf{d}) . * P<0.05, * * P$ $<0.01, * * * P<0.001$ a

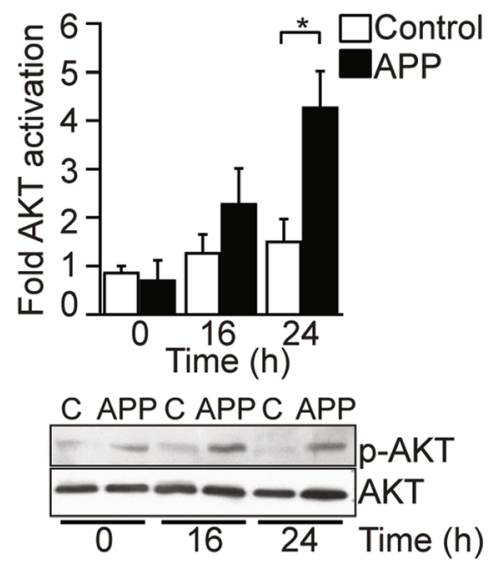

C

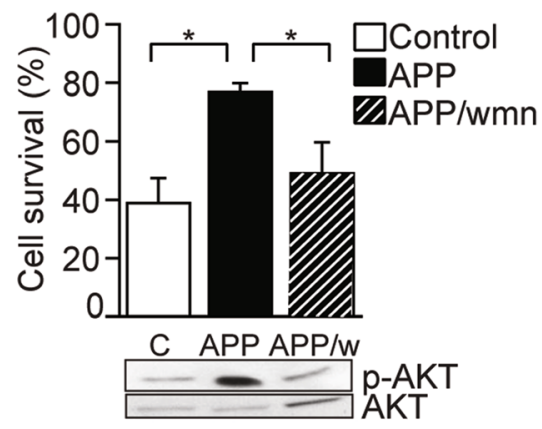

b

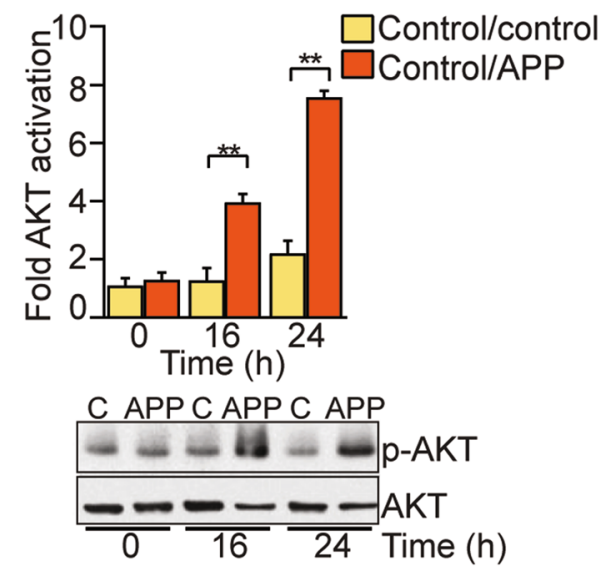

d

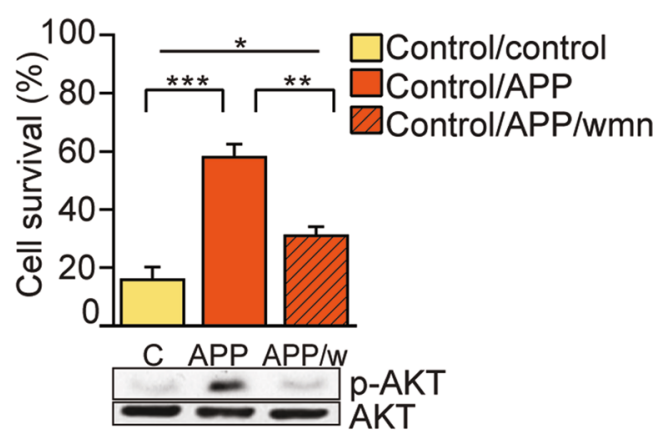

If APP is critical for retinal cell survival after toxic challenge, we hypothesized that mice deficient in APP would show a greater susceptibility to rotenone-induced toxicity. To test this hypothesis, we conducted experiments with mice carrying a homozygous deletion of the APP gene ( $\mathrm{APP}^{-/}$mice). These mice have no detectable levels of APP mRNA or protein but are fertile and do not show overt abnormalities up to 12 weeks of age [28]. Initial histological analysis of baseline retinal cross-sections revealed no overt structural abnormalities in $\mathrm{APP}^{-1-}$ mice (Supplementary Fig. 4). Since we established that rotenone treatment-induced cell loss was localized to the inner nuclear and ganglion cell layers of the retina, analysis on the response of $\mathrm{APP}^{-/-}$mice to rotenone toxicity was focused specifically on these locations. On retinal cross-sections collected $24 \mathrm{~h}$ after rotenone treatment, we quantified soma in the ganglion cell layer and assessed the integrity of the inner nuclear layer by measuring its thickness. Compared to wild-type, $\mathrm{APP}^{-/-}$mice showed a significantly greater loss of retinal ganglion cell layer (GCL) in response to rotenone injection (Fig. 4d). Furthermore, the inner nuclear layer (INL) of $\mathrm{APP}^{-/-}$mice was significantly thinner than that seen in wild-type mice, indicating a greater loss of inner retinal cell bodies in response to rotenone (Fig. 4d). There was no change in the thickness of the outer nuclear layer (ONL), or plexiform layers (OPL/IPL) of the retina in either wild-type or
$\mathrm{APP}^{-/-}$mice with rotenone, indicating no substantial loss of photoreceptors or synaptic connections (Fig. 4d). Collectively, these findings support our in vitro findings and suggest a neuroprotective role for $\operatorname{sAPP} \alpha$ in vivo.

\section{Age-Related Changes to APP Levels in the Human Eye}

There is consistent and substantial evidence for a neuroprotective function of APP and $\operatorname{sAPP} \alpha$ in vivo [16], which is further supported by our current data. However, due to the difficulty in obtaining clinical samples, most of the in vivo work to date has used rodent models and there is little data available on APP and sAPP $\alpha$ in human eye tissue. A previous study using immunoreactivity analysis in a small number of human eyes showed that APP is predominantly located in the inner retina, specifically the ganglion cell and retinal nerve fiber layers [43]. We conducted an analysis of APP and $\operatorname{sAPP} \alpha$ protein levels in retinal tissue and vitreous fluid from a large cohort of human eyes collected over a 3-year period through the Lions Eye Donation Service, Melbourne, Australia (Table 1). Retinal tissue was collected from donors that ranged in age from 5 to 91 years of age $(n=83)$, while vitreous fluid was obtained from donors ranging from 22 to 91 years of age $(n=41)$. Immunoblotting was performed using antibodies that detect full-length APP (\#A8717, 
Fig. 4 APP protects against rotenone-toxicity in the mouse retina. a Expression of APP in the mouse retina was assessed by immunohistochemistry of crosssections using an antibody that detects all APP isoforms and APP fragments (22C11).

Representative images show localization of APP (red) in the retinal ganglion cell layer. Scale bar $=20 \mu \mathrm{m}$. b Cell death in the mouse retina was quantified by the frequency of TUNEL-positive nuclei in the inner retina $24 \mathrm{~h}$ after rotenone toxicity. Data are presented as mean \pm SEM; $n=8$; ${ }^{*} p<0.05$ by Student's $t$ test. c Representative micrographs of mouse retinal cross-sections show TUNEL-positive cells (red). Scale bar $=20 \mu \mathrm{m}$. d Survival of retinal neurons $24 \mathrm{~h}$ after rotenone toxicity in wild-type (WT) and APP knockout $\left(\mathrm{APP}^{-/-}\right)$mice was quantified by measuring the thickness of nuclear and synaptic layers and by counting the number of soma in the ganglion cell layer on nuclear-stained retinal cross-sections. Data are presented as mean \pm SEM; $n=8 ; * p<0.05$ by Student's $t$ test. ONL: outer nuclear layer; OPL: outer plexiform layer; INL: inner nuclear layer; IPL: inner plexiform layer; GCL: ganglion cell layer a
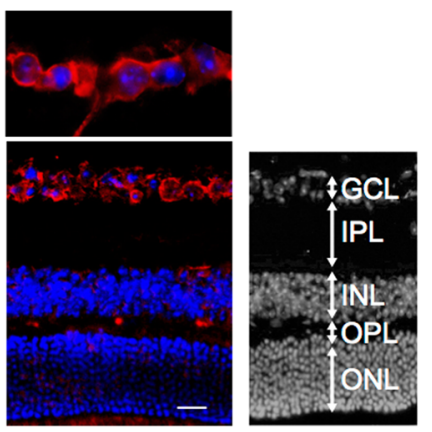

C

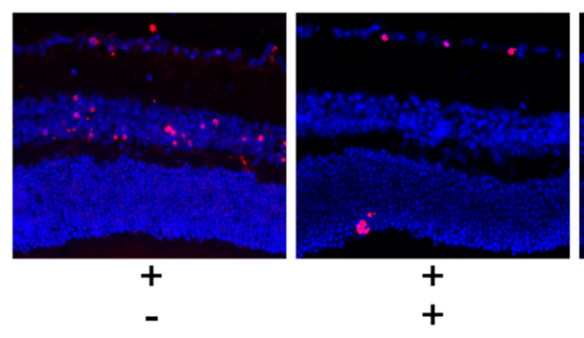

d

b

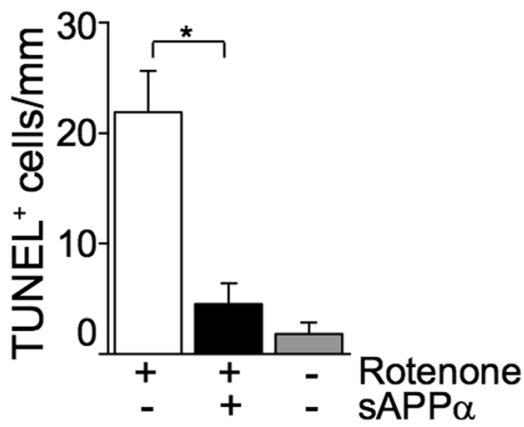

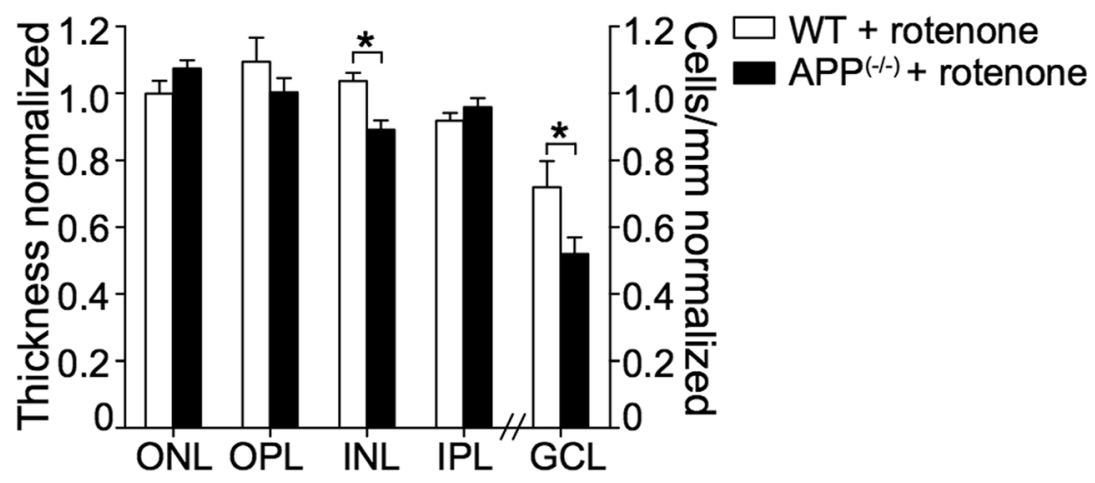

Sigma) or $\operatorname{sAPP} \alpha$ (anti-sAPP $\alpha 2 \mathrm{~B} 3, \mathrm{IBL})$. We detected the presence of both full-length APP and $\operatorname{APP} \alpha$ in human retinal samples (using actin as a loading control) and confirmed only sAPP $\alpha$ in the vitreous samples (Fig. 5a). An absence of full length APP and actin (Fig. 5a) indicated the purity of the vitreous samples and the lack of contamination by retina or other tissue during dissection. By quantifying retinal APP and retinal $\mathrm{SAPP} \alpha$ levels, a linear regression analysis was used to address the relationship between retinal expression and age in the human eyes. While there was a significant decrease in retinal expression of APP with age (Fig. 5b), no change was seen in the levels of retinal $\operatorname{sAPP} \alpha$ (Fig. 5c).
Table 1 Characteristics of donors for aging retina and vitreous analysis

\begin{tabular}{lllll}
\hline Sample type & Subset (years) & $n$ & Sex (female $n ; \%)$ & Age (average, years) \\
\hline Retina & total & 83 & $38(45.8)$ & $59.2 \pm 18.9 ;$ range 5-91 \\
& $<40$ & 16 & $7(43.8)$ & $27.9 \pm 10.6$ \\
& $40-70$ & 37 & $18(48.6)$ & $58.8 \pm 8.2$ \\
Vitreous & $>70$ & 30 & $13(43.3)$ & $76.4 \pm 4.9$ \\
& Total & 41 & $18(43.9)$ & $62.4 \pm 16.5 ;$ range 22-91 \\
& $<40$ & 6 & $2(33.3)$ & $32 \pm 5.3$ \\
& $40-70$ & 18 & $8(44.4)$ & $59.2 \pm 7.4$ \\
& $>70$ & 17 & $8(47.1)$ & $76.6 \pm 6.2$ \\
\hline
\end{tabular}


a retina vitreous

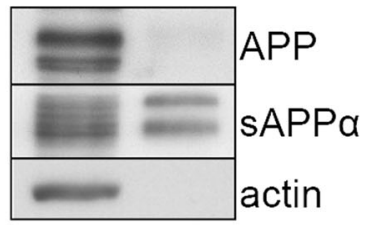

b

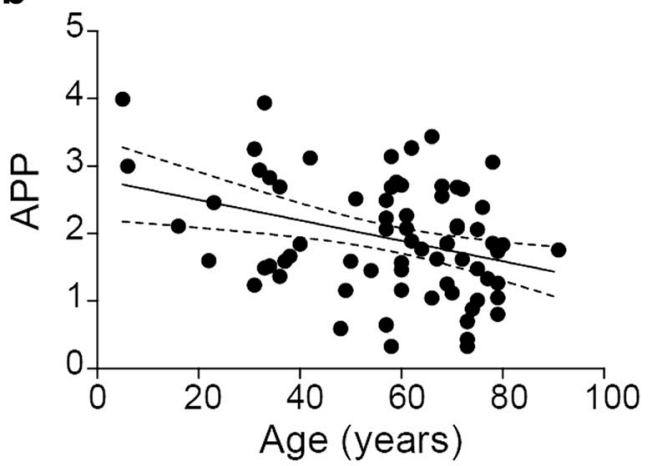

C

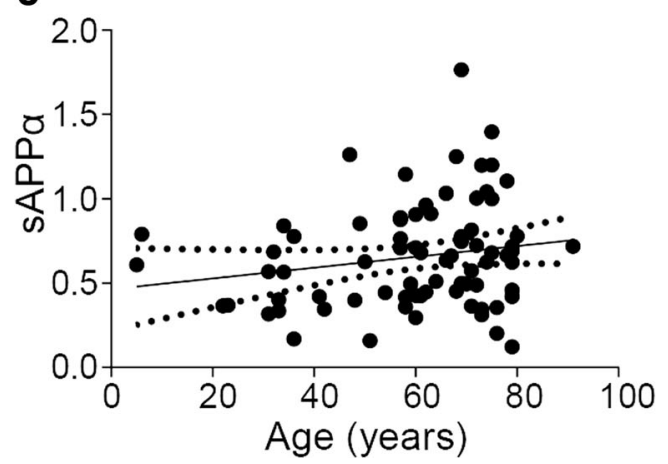

Fig. 5 APP levels decrease in the aging human eye. a Representative image of APP expression in the human eye, assessed by immunoblotting using antibodies against full-length APP (anti-APP $22 \mathrm{C} 11$; Millipore) and $\mathrm{sAPP} \alpha$ (anti-sAPP $\alpha 2 \mathrm{~B} 3$; IBL). Both species of APP were detected in the retina while only $\operatorname{sAPP} \alpha$ was detected in the vitreous. b, c Linear regression analysis of retinal APP (b) and retinal $\operatorname{sAPP} \alpha(\mathbf{c})$ levels and age in the human eye

\section{Discussion}

Here, we investigated the neuroprotective effects of APP and $\operatorname{sAPP} \alpha$ in vitro and in vivo, using models of neurodegeneration induced by rotenone exposure, and report a loss in retinal APP with age in humans. APP confers protection to neuronal cells from rotenone through both autocrine and paracrine mechanisms mediated via the Pi3K/Akt prosurvival pathway. The addition of $\operatorname{sAPP} \alpha$ to primary neuronal cultures under trophic factor deprivation has been shown to reinstate the Pi3K/Akt and ERK pathways and provide protection from cell death [37, 38]. By contrast, the activation of Akt in APP over-expressing cells and cells exposed to $\operatorname{sAPP} \alpha$-enriched media found here was insult-driven. This correlated with the relative preservation of ATP levels as well as the repression of cellular peroxide levels and caspase 3 activity in APP over-expressing cells compared to control cells. Over-expression of APP did not affect rotenone-induced p38 or JNK pathway activation despite $\operatorname{sAPP} \alpha$-mediated JNK suppression being linked to its neuroprotective mechanism against epoxomicin [40]. It did, however, immediately and continually suppress rotenone-induced superoxide levels, which may be a result of the reported doubling of manganese superoxide dismutase levels in APP over-expressing neuroblastoma cells [44].

One reason over-expression of APP protected against rotenone-induced mitochondrial complex I dysfunction and not cyanide-induced mitochondrial complex IV dysfunction may be linked to Akt targets. The cyanide model used here was caspase 3-independent and resulted in a rapid loss of cellular ATP. By promoting the interaction of hexokinase with mitochondria and inhibiting Bax translocation to mitochondria [45], activated Akt effectively prevents mitochondrial cytochrome $c$ release and subsequent caspase 3 activation. This pro-survival pathway would therefore be ineffective against the rapid cyanideinduced cell death observed here.

Using an in vivo model of acute rotenone toxicity in the mouse retina, we showed that intravitreal delivery of recombinant human $\operatorname{sAPP} \alpha$, which lacks the posttranslational modifications present in endogenously processed $\operatorname{sAPP} \alpha$, reduces retinal neuronal cell death in wild-type animals. The same toxicity model in $\mathrm{APP}^{-/}$mice resulted in a greater loss of inner retinal neurons compared to wild-type mice, suggesting that endogenous APP processing provides some protection from the complex I inhibition. Our finding of abundant levels of $\operatorname{sAPP} \alpha$ in human vitreous implicates this neurotrophin in retinal homeostasis. We and others [42] show that retinal ganglion cells have the highest expression of APP in the wild-type mouse retina, which is the most likely source of $\operatorname{sAPP} \alpha$ in the vitreous. Examination of retinal APP protein levels in a large cohort of human eyes illustrate a significant decrease with age, raising the question of whether a loss in APP contributes to age-related neurodegeneration.

The accumulation of $A \beta$ is a traditional hallmark of Alzheimer's disease but other forms of neurodegeneration, including a subset of patients with Parkinson's disease with dementia, have a similar neuropathological observation [46]. However, as the generation of $\mathrm{A} \beta$ or $\mathrm{SAPP} \alpha$ arise from alternative proteolytic pathways of APP it is reasonable to propose that an increase in $A \beta$ production will result in a decrease in sAPP $\alpha$ levels [47]. Increased $A \beta$ production thereby results in both a gain of $A \beta$ toxicity and a potential loss of $\operatorname{sAPP} \alpha$ neurotrophic/neuroprotective function. Lower $\operatorname{SAPP} \alpha$ levels have been found in cerebro-spinal fluid of Alzheimer's disease patients carrying the Swedish mutations in APP [48] and in post mortem brain [49], but pre-mortem studies in cerebrospinal fluid or blood in patients with sporadic Alzheimer's disease have not provided consistent results [50]. Few studies 
have investigated APP levels in Parkinson's disease brain. However, Ayton et al. showed lower APP levels in post mortem Parkinson's disease substantia nigra, and mice overexpressing APP are protected from MPTP-induced nigral cell loss [51]. This is consistent with our findings as both rotenone and the neurotoxin $\mathrm{MPP}^{+}$(derived from MPTP) are potent mitochondrial complex I inhibitors.

\section{Conclusions}

In summary, we show that APP over-expression or exposure to $\mathrm{sAPP} \alpha$ affords protection from mitochondrial complex I inhibition by rotenone. This protection is driven by $\mathrm{Pi} 3 \mathrm{~K} /$ Akt activation. Our finding that $\operatorname{APP} \alpha$ can protect from acute rotenone toxicity provides therapeutic insights into mitochondrial neurodegeneration. Pharmacological mimetics of this protection mechanism could be promising therapeutic candidates in diseases resulting from complex I impairment including mitochondrial optic neuropathies and Parkinson's disease.

Acknowledgements We acknowledge the valuable support of the Lions Eye Donation Service, Melbourne, Australia in this project.

Authors' Contributions KC, HSW, VC, MIGLS, and VAJ conducted experiments and prepared data figures;

MJC, JGC, and AIB provided critical advice and support;

JD and AFH supplied reagents and technical support;

IAT designed experiments;

$\mathrm{KC}, \mathrm{VC}$, MIGLS, JD, and IAT wrote the manuscript.

All authors read and approved the final manuscript.

Funding This research was supported by the BrightFocus Foundation Thomas R. Lee award (G2009020), the DHB Foundation (IAT) and the Mason Foundation (IAT and JAD). CERA receives Operational Infrastructure Support from the Victorian Government, Australia.

\section{Compliance with Ethical Standards}

Ethics All procedures conformed to the requirements of the Royal Victorian Eye \& Ear Hospital Animal Research and Ethics Committee. Wild-type and $\mathrm{APP}^{-/-}$mice on a SV129 background [28] originated from a breeding colony at the Melbourne Brain Centre, Melbourne VIC, Australia. Mice were housed in a temperature $\left(22 \pm 1{ }^{\circ} \mathrm{C}\right)$ and light (12 $\mathrm{h}$ light, $12 \mathrm{~h}$ dark) controlled environment where food and water were available ad libitum. Male and female mice were used equally. Work involving human eyes was carried out in accordance of the Declaration of Helsinki. All experimental procedures were approved by the Royal Victorian Eye and Ear Hospital Human Research Ethics Committee (Project $08 / 859 \mathrm{H}$ ) and written informed consent was obtained from all next of kin or participants.

Conflicts of Interest The authors declare that they have no conflicts of interest.

Research Involving Human Participants and/or Animals Work involving human eyes was carried out in accordance of the Declaration of Helsinki. All experimental procedures were approved by the Royal Victorian Eye and Ear Hospital Human Research Ethics Committee
(Project 08/859H). All procedures involving animals conformed to the requirements of the Royal Victorian Eye \& Ear Hospital Animal Research and Ethics Committee.

Informed Consent Human eyes were donated for research purposes through the Lions Eye Donation Service (Melbourne, Australia) and written informed consent was obtained from all next of kin or participants.

Abbreviations Akt, protein kinase B; APP, amyloid precursor protein; $\mathrm{A} \beta$, amyloid beta; DCFH, 2,7-dichlorodihydrofluorescein; DHE, dihydroethidine; ERK, extracellular-signal-regulated kinase; FBS, fetal bovine serum; GCL, ganglion cell layer; INL, inner nuclear layer; IPL, inner plexiform layer; JNK, c-Jun N-terminal kinase; MAPK, mitogenactivated protein kinase; $\mathrm{MPP}^{+}$, 1-methyl-4-phenylpyridinium; MPTP, 1methyl-4-phenyl-1,2,3,6-tetrahydropyridine; NADH, nicotinamide adenine dinucleotide + hydrogen; ONL, outer nuclear layer; OPL, outer plexiform layer; OXPHOS, oxidative phosphorylation; PBS, phosphatebuffered saline; Pi3K, phosphatidylinositol-3-kinase; ROS, reactive oxygen species; $\operatorname{sAPP} \alpha$, soluble amyloid precursor protein alpha; TUNEL, terminal deoxynucleotidyl transferase dUTP nick-end labeling; Wmn, wortmannin

Open Access This article is distributed under the terms of the Creative Commons Attribution 4.0 International License (http:// creativecommons.org/licenses/by/4.0/), which permits unrestricted use, distribution, and reproduction in any medium, provided you give appropriate credit to the original author(s) and the source, provide a link to the Creative Commons license, and indicate if changes were made.

Publisher's Note Springer Nature remains neutral with regard to jurisdictional claims in published maps and institutional affiliations.

\section{References}

1. Janssen RJ, van den Heuvel LP, Smeitink JA (2004) Genetic defects in the oxidative phosphorylation (OXPHOS) system. Expert Rev Mol Diagn 4(2):143-156. https://doi.org/10.1586/14737159.4.2. 143

2. Lopez Sanchez MI, Crowston JG, Mackey DA, Trounce IA (2016) Emerging mitochondrial therapeutic targets in optic neuropathies. Pharmacol Ther 165:132-152. https://doi.org/10.1016/j. pharmthera.2016.06.004

3. Mimaki M, Wang X, McKenzie M, Thorburn DR, Ryan MT (2012) Understanding mitochondrial complex I assembly in health and disease. Biochim Biophys Acta 1817(6):851-862. https://doi.org/ 10.1016/j.bbabio.2011.08.010

4. Scheffler IE (2015) Mitochondrial disease associated with complex I (NADH-CoQ oxidoreductase) deficiency. J Inherit Metab Dis 38(3):405-415. https://doi.org/10.1007/s10545-014-9768-6

5. Schapira AH, Cooper JM, Dexter D, Clark JB, Jenner P, Marsden CD (1990) Mitochondrial complex I deficiency in Parkinson's disease. J Neurochem 54(3):823-827

6. Lee S, Sheck L, Crowston JG, Van Bergen NJ, O'Neill EC, O'Hare F et al (2012) Impaired complex-I-linked respiration and ATP synthesis in primary open-angle glaucoma patient lymphoblasts. Invest Ophthalmol Vis Sci 53(4):2431-2437. https://doi.org/10.1167/iovs. 12-9596

7. Van Bergen NJ, Crowston JG, Craig JE, Burdon KP, Kearns LS, Sharma S et al (2015) Measurement of systemic mitochondrial function in advanced primary open-angle Glaucoma and Leber hereditary optic neuropathy. PLoS One 10(10):e0140919. https://doi. org/10.1371/journal.pone.0140919 
8. Brown MD, Trounce IA, Jun AS, Allen JC, Wallace DC (2000) Functional analysis of lymphoblast and cybrid mitochondria containing the 3460,11778 , or 14484 Leber's hereditary optic neuropathy mitochondrial DNA mutation. J Biol Chem 275(51):3983139836. https://doi.org/10.1074/jbc.M006476200

9. Betarbet R, Sherer TB, MacKenzie G, Garcia-Osuna M, Panov AV, Greenamyre JT (2000) Chronic systemic pesticide exposure reproduces features of Parkinson's disease. Nat Neurosci 3(12):13011306. https://doi.org/10.1038/81834

10. Blesa J, Przedborski S (2014) Parkinson's disease: Animal models and dopaminergic cell vulnerability. Front Neuroanat 8:155. https:// doi.org/10.3389/fnana.2014.00155

11. Zhang X, Jones D, Gonzalez-Lima F (2006) Neurodegeneration produced by rotenone in the mouse retina: A potential model to investigate environmental pesticide contributions to neurodegenerative diseases. J Toxicol Environ Health Part A 69(18):1681-1697. https://doi.org/10.1080/15287390600630203

12. Hajee ME, March WF, Lazzaro DR, Wolintz AH, Shrier EM, Glazman S, Bodis-Wollner IG (2009) Inner retinal layer thinning in Parkinson disease. Archives of ophthalmology (Chicago, Ill : 1960) 127(6):737-741. https://doi.org/10.1001/archophthalmol. 2009.106

13. Jimenez B, Ascaso FJ, Cristobal JA, Lopez del Val J (2014) Development of a prediction formula of Parkinson disease severity by optical coherence tomography. Mov Disord 29(1):68-74. https://doi.org/10.1002/mds.25747

14. Ahn J, Lee JY, Kim TW, Yoon EJ, Oh S, Kim YK, Kim JM, Woo SJ et al (2018) Retinal thinning associates with nigral dopaminergic loss in de novo Parkinson disease. Neurology 91:e1003-e1012. https://doi.org/10.1212/wnl.0000000000006157

15. Bose A, Beal MF (2016) Mitochondrial dysfunction in Parkinson's disease. J Neurochem 139(Suppl 1):216-231. https://doi.org/10. 1111/jnc. 13731

16. Kogel D, Deller T, Behl C (2012) Roles of amyloid precursor protein family members in neuroprotection, stress signaling and aging. Exp Brain Res 217(3-4):471-479. https://doi.org/10.1007/s00221011-2932-4

17. Zheng H, Koo EH (2006) The amyloid precursor protein: Beyond amyloid. Mol Neurodegener 1:5. https://doi.org/10.1186/17501326-1-5

18. Kojro E, Fahrenholz F (2005) The non-amyloidogenic pathway: Structure and function of alpha-secretases. Subcell Biochem 38: $105-127$

19. Haass C, Hung AY, Schlossmacher MG, Teplow DB, Selkoe DJ (1993) Beta-amyloid peptide and a 3-kDa fragment are derived by distinct cellular mechanisms. J Biol Chem 268(5):3021-3024

20. Vassar R, Bennett BD, Babu-Khan S, Kahn S, Mendiaz EA, Denis $P$ et al (1999) Beta-secretase cleavage of Alzheimer's amyloid precursor protein by the transmembrane aspartic protease BACE. Science (New York, NY) 286(5440):735-741

21. Jarrett JT, Berger EP, Lansbury PT Jr (1993) The carboxy terminus of the beta amyloid protein is critical for the seeding of amyloid formation: Implications for the pathogenesis of Alzheimer's disease. Biochemistry 32(18):4693-4697

22. Mann DM, Iwatsubo T, Ihara Y, Cairns NJ, Lantos PL, Bogdanovic $\mathrm{N}$ et al (1996) Predominant deposition of amyloid-beta 42(43) in plaques in cases of Alzheimer's disease and hereditary cerebral hemorrhage associated with mutations in the amyloid precursor protein gene. Am J Pathol 148(4):1257-1266

23. Plummer S, Van den Heuvel C, Thornton E, Corrigan F, Cappai R (2016) The neuroprotective properties of the amyloid precursor protein following traumatic brain injury. Aging Disease 7(2):163179. https://doi.org/10.14336/ad.2015.0907

24. Ayton S, Zhang M, Roberts BR, Lam LQ, Lind M, McLean C, Bush AI, Frugier T et al (2014) Ceruloplasmin and beta-amyloid precursor protein confer neuroprotection in traumatic brain injury and lower neuronal iron. Free Radic Biol Med 69:331-337. https:// doi.org/10.1016/j.freeradbiomed.2014.01.041

25. Clarke J, Thornell A, Corbett D, Soininen H, Hiltunen M, Jolkkonen J (2007) Overexpression of APP provides neuroprotection in the absence of functional benefit following middle cerebral artery occlusion in rats. Eur J Neurosci 26(7):1845-1852. https:// doi.org/10.1111/j.1460-9568.2007.05807.x

26. Lopez Sanchez MIG, Waugh HS, Tsatsanis A, Wong BX, Crowston JG, Duce JA, Trounce IA (2017) Amyloid precursor protein drives down-regulation of mitochondrial oxidative phosphorylation independent of amyloid beta. Sci Rep 7(1):9835. https://doi.org/10.1038/s41598-017-10233-0

27. Qin W, Haroutunian V, Katsel P, Cardozo CP, Ho L, Buxbaum JD, Pasinetti GM (2009) PGC-1alpha expression decreases in the Alzheimer disease brain as a function of dementia. Arch Neurol 66(3):352-361. https://doi.org/10.1001/archneurol.2008.588

28. Zheng H, Jiang M, Trumbauer ME, Hopkins R, Sirinathsinghji DJ, Stevens KA et al (1996) Mice deficient for the amyloid precursor protein gene. Ann N Y Acad Sci 777:421-426

29. McKenzie M, Chiotis M, Hroudova J, Lopez Sanchez MI, Lim SC, Cook MJ et al (2014) Capture of somatic mtDNA point mutations with severe effects on oxidative phosphorylation in synaptosome cybrid clones from human brain. Hum Mutat 35(12):1476-1484. https://doi.org/10.1002/humu.22694

30. Chrysostomou V, Kezic JM, Trounce IA, Crowston JG (2014) Forced exercise protects the aged optic nerve against intraocular pressure injury. Neurobiol Aging 35(7):1722-1725. https://doi. org/10.1016/j.neurobiolaging.2014.01.019

31. Chrysostomou V, Crowston JG (2013) The photopic negative response of the mouse electroretinogram: Reduction by acute elevation of intraocular pressure. Invest Ophthalmol Vis Sci 54(7):46914697. https://doi.org/10.1167/iovs.13-12415

32. Maslim J, Valter K, Egensperger R, Hollander H, Stone J (1997) Tissue oxygen during a critical developmental period controls the death and survival of photoreceptors. Invest Ophthalmol Vis Sci 38(9):1667-1677

33. Tanner CM, Kamel F, Ross GW, Hoppin JA, Goldman SM, Korell M, Marras C, Bhudhikanok GS et al (2011) Rotenone, paraquat, and Parkinson's disease. Environ Health Perspect 119(6):866-872. https://doi.org/10.1289/ehp.1002839

34. Borland MK, Trimmer PA, Rubinstein JD, Keeney PM, Mohanakumar K, Liu L, Bennett JP Jr (2008) Chronic, low-dose rotenone reproduces Lewy neurites found in early stages of Parkinson's disease, reduces mitochondrial movement and slowly kills differentiated SH-SY5Y neural cells. Mol Neurodegener 3:21. https://doi.org/10.1186/1750-1326-3-21

35. Arnold S (2012) Cytochrome c oxidase and its role in neurodegeneration and neuroprotection. Adv Exp Med Biol 748:305-339. https://doi.org/10.1007/978-1-4614-3573-0_13

36. Li N, Ragheb K, Lawler G, Sturgis J, Rajwa B, Melendez JA, Robinson JP (2003) Mitochondrial complex I inhibitor rotenone induces apoptosis through enhancing mitochondrial reactive oxygen species production. J Biol Chem 278(10):8516-8525. https:// doi.org/10.1074/jbc.M210432200

37. Milosch N, Tanriover G, Kundu A, Rami A, Francois JC, Baumkotter F et al (2014) Holo-APP and G-protein-mediated signaling are required for sAPPalpha-induced activation of the Akt survival pathway. Cell Death Dis 5:e1391. https://doi.org/10. 1038/cddis.2014.352

38. Cheng G, Yu Z, Zhou D, Mattson MP (2002) Phosphatidylinositol3-kinase-Akt kinase and p42/p44 mitogen-activated protein kinases mediate neurotrophic and excitoprotective actions of a secreted form of amyloid precursor protein. Exp Neurol 175(2):407-414. https://doi.org/10.1006/exnr.2002.7920

39. Jimenez S, Torres M, Vizuete M, Sanchez-Varo R, Sanchez-Mejias E, Trujillo-Estrada L, Carmona-Cuenca I, Caballero C et al (2011) 
Age-dependent accumulation of soluble amyloid beta (Abeta) oligomers reverses the neuroprotective effect of soluble amyloid precursor protein-alpha (SAPP(alpha)) by modulating phosphatidylinositol 3-kinase (PI3K)/Akt-GSK-3beta pathway in Alzheimer mouse model. J Biol Chem 286(21):18414-18425. https://doi.org/10.1074/jbc.M110.209718

40. Copanaki E, Chang S, Vlachos A, Tschape JA, Muller UC, Kogel D, Deller T (2010) sAPPalpha antagonizes dendritic degeneration and neuron death triggered by proteasomal stress. Mol Cell Neurosci 44(4):386-393. https://doi.org/10.1016/j.men.2010.04. 007

41. Newhouse K, Hsuan SL, Chang SH, Cai B, Wang Y, Xia Z (2004) Rotenone-induced apoptosis is mediated by p38 and JNK MAP kinases in human dopaminergic SH-SY5Y cells. Toxicol Sci 79(1):137-146. https://doi.org/10.1093/toxsci/kfh089

42. Ho T, Vessey KA, Cappai R, Dinet V, Mascarelli F, Ciccotosto GD, Fletcher EL (2012) Amyloid precursor protein is required for normal function of the rod and cone pathways in the mouse retina. PLoS One 7(1):e29892. https://doi.org/10.1371/journal.pone. 0029892

43. Loffler KU, Edward DP, Tso MO (1995) Immunoreactivity against tau, amyloid precursor protein, and beta-amyloid in the human retina. Invest Ophthalmol Vis Sci 36(1):24-31

44. Kogel D, Schomburg R, Copanaki E, Prehn JH (2005) Regulation of gene expression by the amyloid precursor protein: Inhibition of the JNK/c-Jun pathway. Cell Death Differ 12(1):1-9. https://doi. org/10.1038/sj.cdd.4401495

45. Majewski N, Nogueira V, Bhaskar P, Coy PE, Skeen JE, Gottlob K, Chandel NS, Thompson CB et al (2004) Hexokinase-mitochondria interaction mediated by Akt is required to inhibit apoptosis in the presence or absence of Bax and Bak. Mol Cell 16(5):819-830. https://doi.org/10.1016/j.molcel.2004.11.014

46. Emre M, Aarsland D, Brown R, Burn DJ, Duyckaerts C, Mizuno Y, Broe GA, Cummings J et al (2007) Clinical diagnostic criteria for dementia associated with Parkinson's disease. Mov Disord 22(12): 1689-1707; quiz 1837. https://doi.org/10.1002/mds.21507

47. Busciglio J, Pelsman A, Wong C, Pigino G, Yuan M, Mori H, Yankner BA (2002) Altered metabolism of the amyloid beta precursor protein is associated with mitochondrial dysfunction in Down's syndrome. Neuron 33(5):677-688

48. Lannfelt L, Basun H, Wahlund LO, Rowe BA, Wagner SL (1995) Decreased alpha-secretase-cleaved amyloid precursor protein as a diagnostic marker for Alzheimer's disease. Nat Med 1(8):829-832

49. Hesse R, von Einem B, Wagner F, Bott P, Schwanzar D, Jackson RJ, Föhr KJ, Lausser L et al (2018) sAPPbeta and sAPPalpha increase structural complexity and $\mathrm{E} / \mathrm{I}$ input ratio in primary hippocampal neurons and alter ca(2+) homeostasis and CREB1-signaling. Exp Neurol 304:1-13. https://doi.org/10.1016/j.expneurol. 2018.02.010

50. Habib A, Sawmiller D, Tan J (2017) Restoring soluble amyloid precursor protein alpha functions as a potential treatment for Alzheimer's disease. J Neurosci Res 95(4):973-991. https://doi. org/10.1002/jnr.23823

51. Ayton S, Lei P, Hare DJ, Duce JA, George JL, Adlard PA, McLean C, Rogers JT et al (2015) Parkinson's disease iron deposition caused by nitric oxide-induced loss of beta-amyloid precursor protein. $\mathrm{J}$ Neurosci 35(8):3591-3597. https://doi.org/10.1523/jneurosci. $3439-14.2015$ 